\title{
ENSINO CENTRADO NO ESTUDANTE: ORIENTAÇÃO À DISCIPLINA ENFERMAGEM PEDIÁTRICA - NFVEL GRADUAÇÃO
}

\author{
Edelia del Pilar Neira Huerta* \\ Margareth Angelo * \\ Moneda Oliveira Ribeiro** \\ Ana Lúcia de Moraes Horta**
}

NEIRA HUERTA, E. del P.; ANGELO, M.; RIBEIRO, M.O.; HORTA, A.L. de M. Ensino centrado no estudante: orientação à disciplina Enfermagem Pediátrica nivel graduação. Rev. Esc. Enf. USP, São Paulo, 20(2)101-114, 1986.

As autoras apresentam o material atualmente fornecido aos alunos para orientaşão à disciplina Enfermagem Pediátrica I da Escola de Enfermagem da USP, cuja metodologia de ensino é centrada no estudante.

\section{INTRODUÇÃO}

Desde 1979 as docentes da disciplina Enfermagem Pediátrica da Escola de Enfermagem da USP utilizam a metodologia de ensino centrado no estudante, observando, nos 20 grupos de alunos que, até o momento experimentaram essa metodologia, resultados que permitem constatar a ocorrência de aprendizado mais efetivo de enfermagem pediátrica do que no método tradicional antes empregado (MORAES ${ }^{1}$, MORAES \& PAULA ${ }^{2}$, RIBEIRO et alii ${ }^{5}$, NEIRA HUERTA et alii ${ }^{3}$ ).

No entanto, apesar desses resultados, o inicio da disciplina nem sempre tem sido fácil para a maior parte dos alunos. Após análise das observaçōes realizadas nos primeiros grupos foi possivel identificar que parte dessa realidade era conseqüência da dificuldade dos alunos em compreender a maneira como a disciplina aconteceria, bem como aquilo que deles era esperado (NEIRA HUERTA \& ANGELO ${ }^{4}$ ).

Após utilizarmos diferentes formas de orientação à disciplina, percebemos que as informações, além de não serem compreendidas na integra, eram também esquecidas pelos alunos, por serem apresentadas oralmente. Por isso, e acreditando que o resultado da metodologia tam-

* Enfermeira. Mestre em Enfermagem. Professor Assistente do Departamento de Enfermagem Materno-Infantil e Psiquiátrica da Escola de Enfermagem da USP - disciplina Bnfermagem Pediatrica.

** Enfermeira. Auxiliar de Ensino do Departamento de Enfermagem Materno-Infantil $\theta$ Pslquíátrica da Escola de Enfermagem da USP - disciplina Enfermagem Pediatrica. 
bém depende da maneira como é compreendida, elaboramos um material contendo todas as informações acêrca do funcionamento da disciplina, que é entregue aos alunos no primeiro dia de atividades conosco.

O objetivo deste trabalho é apresentar na íntegra esse material, atualmente utilizado na orientação à disciplina.

\title{
ORIENTAÇÃO À DISCIPLINA ENFERMAGEM PEDIATRICA I
}

\author{
UNIVERSIDADE DE SAO PAULO \\ ESCOLA DE ENFERMLAGEM
}

DEPARTAMENTO DE ENFERMAGEM MATERNO-INFANTTL E PSIQUIATRICA

DISCIPLINA ENFERMAGEM PEDIATRICA I

Apresentação

$\begin{array}{lrl}\text { Periodo: } & 8 & \text { semanas } \\ \text { Carga Horária: } & 270 & \text { horas } \\ \text { - atividades téricas: } & 120 & \text { horas } \\ \text { - atividades práticas: } & 120 & \text { horas } \\ \text { - crédito - trabalho: } & 30 \text { horas }\end{array}$

Olá !

Nós, Edélia, Margareth, Moneda e Ana Lúcia, somos as docentes responsáveis pela disciplina que você vai cursar agora. Este é o nosso primeiro contato e, como dele depende boa parte do curso, achamos importante que certos pontos básicos fiquem bem esclarecidos entre nós. Por isso leia com atenção o que segue e converse conosco sobre suas dúvidas.

Para começar, gostariamos de dizer que esta não é uma disciplina do tipo tradicional. Ela depende das pessoas que a compõem, ou seja, de você, de nós, de todo o grupo. Ela acontece a partir de um prccesso ativo que requer envolvimemto, participação e compromisso do grupo: alunas e docentes. Isto torna imprescindivel o envolvimento pessoal, de maneira que você não poderá ter papel passivo. Por se tratar de uma disciplina acontece de maneira diferente, é sobre ela que queremos falar com você.

Convidamos você a participar da leitura do material que segue e a esclarecer suas dúvidas com as colegas e conosco.

\section{COMO FUNCIONA ESTA DISCIPLINA}

Esta, como todas contém cinco elementos básicos: pessoas - interações - conteúdo - processo ou método - pressão institucional. A atividade de um curso envolve diferentes combinações desses cinco elementos. Esta disciplina dá mais ênfase às PESSOAS E INTERAÇõES, acreditando que assim lidaremos de um modo mais criativo e construtivo com o conteúdo e, ainda, certa maneira mais realista de lidar com a pressão institucional. 


\section{PESSOAS}

Compreendemos que a pessoa em processo de aprendizagem, ou seja, VOCE:

- desenvolve-se segundo ritmo próprio e a seu próprio modo, obedecendo a um fator essencial ao desenvolvimento pessoal, a motivação;

- deve ter liberdade para aprender, isto é, liberdade para perceber e encaminhar seus sentimentos, idéias, necessidades e objetivos nas diferentes experiências de aprendizagem; e

- deve sentir-se comprometida e participar ativamente de sua aprendizagem.

Para incentivar o desenvolvimento dessas caracteristicas da pessoa em processo de aprendizagem, a maior parte dos periodos do curso serão centrados na pessoa: VOCE.

\section{INTERAÇÕES}

As interações referem-se ao interrelacionamento das pessoas no curso. Achamos que você deve participar de todas as aportunidades de interrelacionamento do curso, isto é, de todos os contatos que forem programados, sejam eles da classe toda ('grupão'), de pequenos grupos ou individuais, porque em cada um deles vemos uma oportunidade de aprendizagem.

Você terá apoio para deixar de comparecer quando sentir que a atividade em que está empenhada tem maior significado para você do que o contato planejado pela classe. Isto não quer dizer que a sua presença - ou sua ausência - seja indiferente para nós. Esse motivo nos levará a buscar contato com você quando não estiver participando, parax podermos compreender as razões do seu afastamento; só a' partir dai o apoio poderá ocorrer. Afinal, você deve sentir-se comprometida com o grupo. VOCE E PARTE DELE.

Aqueles contatos que consideramos básicos já estão programados da seguinte maneira:

- as interações de 'grupão', cujo objetivo é promover encontros do grupo como um todo, encontros estes que poderão ser destinados a discussões, relatos de experiência, decisões, compreensão do desenvolvimento, do curso e do grupo, entre outros. Estes contatos acontecerão semanalmente;

- as reuniōes de pequenos grupos, cuja finalidade é a auto-reflexão sobre o aprendizado e compreensão de necessidades, motivações e dificuldades pessoais, ocorrerão toda semana; e

- os contatos individuais destinados à verbalização das experiências, para sua melhor auto-compreensão, acontecerão toda vez que forem solicitados, por você ou por nós. 
Além desses, em qualquer momento do curso, cada um de nós, integrantes do grupo, pode solicitar outros contatos do tipo que julgar mais adequado.

Gcstariamos de falar um pouco sobre o seu COMPROMISSO COM O GRUPO. Este grupo é seu. Não importa quão difícil lhe seja, participe: através do envolvimento com o processo e com os outros, da assiduidade, da pontualidade; arriscando-se a assumindo-se como PESSOA; SENDO VOCE MESMA!

A seguir apresentamo-lhes algumas formas de comportamento dentro de um grupo que expressam COMPROMISSO com ele e, que não precisam se restringir a este GRUPO - elas são válidas para qualquer interação, em qualquer hora e lugar:

- tente questionar, desafiar, dizer o que sente; procure ser tão honesta e aberta quanto lhe for possivel. Procure compreender, não apenas seus próprios sentimentos, mas também, e principalmente, os sentimentos dos outros;

- não espere por uma pausa maior para falar o que pensa, sente e quer; você pode FAZER suas próprias aberturas. Da mesma forma, quando estiver aborrecida com algum membro do grupo, cujas palavras você acha que não levam a nada, interrompa;

- sendo seu GRUPO, se ele estiver indo num sentido que não lhe agrade, expresse sua insatisfação;

- procure dar seu depoimento pessoal, declarando COISAS SUAS, evitando usar generalidades como: nós, eles, a gente; use EU;

- procure tocar em áreas que lhe causem ansiedade dentro do grupo; fale de seus medos surgidos no decorrer do curso ou anteriores a ele; e

- não se preocupe em parecer tola, descontrolada ou até maluca; se você fizer ou disser o que está sentindo, o grupo provavelmente virá em seu auxilio.

\section{CONTEŨDO}

A enfermagem pediátrica e os elementos que a compõem estão por ai espalhados, acontecendo o tempo todo. Nossa experiência como enfermeiras pediátricas nos permitiu ordenar esses elementos, segundo nossa percepção, naquilo que julgamos constante e básico em enfermagem pediátrica e que caracteriza as funçōes da enfermeira nessa área. (Anexos 1 e 2).

Além dos aspectos relativos à criança e sua família, e das questões relacionadas à enfermagem aplicada à criança e família, VOC $\hat{E}$, em processo de aprendizagem em enfermagem pediátrica, também forma parte do conteúdo, já que o propósito deste curso não é apenas aprender sobre a matéria, mas aprender essa matéria como pessoas inteiras. 
Pelas considerações acima, delineamos como objetivos para o curso, sensibilizar o aluno para:

- caracterizar a criança;

- identificar as necessidades da criança que precisam ser atendidas;

- selecionar o que pode ser executado com os recursos do meio ambiente;

- determinar e executar aspectos da assistència que deseje vivenciar de acordo com seus recursos pessoais e necessidades de aprendizagem; e

- estabelecer os contatos necessários, seja com a equipe de enfermagem, a equipe de saúde ou recursos da comunidade para completar a assistência à criança e sua familia.

\section{PROCESSO OU MÉTODO}

O método diz respeito a como relacionamos conteúdo e pessoas dentro dos limites impostos pela pressão institucional.

O processo ou método do nosso curso é um em que docentes e estudantes, JUNTOS, colaboram no planejamento e implementação das atividades que auxiliarão as alunas na consecução de seus objetivos.

Gostariamos de lhe expor os motivos que nos levaram a optar por cste modo de ser no curso.

1. No que acreditamos. Nós acreditamos que:

- todo o ser humano possui potencial para sentir, pensar, procurar os recursos necessários e agir na solução de seus próprios problemas e no atendimento de suas necessidades;

- é possivel criar um clima aceitador no qual a pessoa se sinta interiormente livre para ser ela própria, detenha o poder sobre si mesma e onde tenha a oportunidade de desenvolver todas suas capacidades;

- ninguém ensina nada a ninguém, mas é possível facilitar a aprendizagem de alguém;

- a verdadeira aprendizagem - aprendizagem significativa abrange idéias e sentimentos, a pessoa como um todo;

- a tendência básica atualizante é a MOTIVAÇÃO, esta impele a pessoa a buscar experiências que propiciem seu crescimento;

- ninguém melhor do que a própria pessoa para avaliar a extensão e o significado de sua experiência, de seu aprendizado; e

- o hábito de refletir sobre as próprias vivências favorece o autoconhecimento, o qual facilita a tomada de decisões quanto à direção da própria aprendizagem e à auto-avaliação. 
2. O que queremos oferecer:

Queremos oferecer a VOCE uma oportunidade de aprendizagem cognitiva-afetiva-vivencial de enfermagem pediátrica; uma oportunidade em que estejam presentes não apenas o seu PENSAR, mas também o seu SENTIR, O SEU QUERER E O SEU AGIR - tudo isso é VOCÊ APRENDENDO - junto com alguns recursos que possibilitem esse tipo de aprendizagem. (Anexos 3 e 4).

Sem intenção de ser repetitivas gostariamos de salientar aquelas caracteristicas que consideramos fundamentais nesta metodologia:

- responsabilidade compartilhada pelo processo de aprendizagem;

- motivação como base para as experiências de aprendizagem;

- decisões quanto à direção da própria aprendizagem;

- professor como facilitador da aprendizagem;

- auto-disciplina para alcançar os objetivos;

- abrangência de idéias e sentimentos;

- auto-avaliação da extensão e significado da aprendizagem.

Estas características implicam nas seguintes funções, para você e para nós.

\section{SÃO SUAS FUNÇÕES}

1. definir o que quer aprender e estabelecer seus próprios objetivos de aprendizagem de enfermagem pediátrica;

2. elaborar um plano de trabalho e levá-lo à prática;

3. utilizar os recursos disponiveis e buscar outros que complementem ou faltem;

4. colaborar ativamente com os demais na consecução dos objetivos pessoais e grupais;

5. avaliar seu próprio trabalho, extensão e significado de sua aprendizagem; e

6. cumprir todas as exigências do curso.

\section{SÃO NOSSAS FUNÇÕES}

1. auxiliá-la na identificação e esclarecimento de seus objetivos de aprendizagem de enfermagem pediátrica;

2. organizar e tornar acessiveis recursos para o processo de aprendizagem; e

3. oferecer-lhe um clima facilitador da aprendizagem. 


\section{PRESSÃO INSTITUCIONAL}

Esta se refere aos limites que a universidade nos impõe e que escapam ao nosso controle: por exemplo, nós temos de dar notas no final do curso; isto é independente da nossa vontade. Trabalhamos numa instituição que exige certo gênero de avaliação do trabalho do estudante. Assim, você sentirá a pressão institucional em termos de exigências do curso.

Apenas isso já nos parece justificativa para cobrar de você o cumprimeito dessas exigências, mas também temos uma posição pessoal em relação a essa avaliação: sentimo-nos responsáveis por colocar à dispasição da criança, de sua família e da comunidade, colegas enfermeiras que tenham pelo menos o mínimo indispensável de formação em enfermagem pediátrica!

\section{EXIGENCIAS DO CURSO}

\section{Folha de Controle de Freqüência}

Nela você deverá registrar diariamente toda as suas atividades, tanto teóricas (leituras em grupo ou individuais, discussões em grupo, aulas, palestras, contato inicial com campos de estágio, etc.) como práticas (estágios, reuniões de pequeno grupo ou com diferentes profissionais que ocorram nos periodos de estágio, visitas a instituições, etc.) bem como o total de horas que você dedicar a ambos os tipos de atividades.

Como consta no inicio deste material, durante o curso você deve computar 120 horas de atividades teóricas e igual número nas práticas. Como nas outras disciplinas, o mínimo de freqüência para poder ser aprovada neste curso é de $70 \%$ em cada um desses tipos de atividades.

Em relação às 30 horas - crédito trabalho, elas deverão ser dedicadas ao preparo de todos os itens considerados como exigência, exceto o item número 3 (Contrato Pessoal de Trabalho).

A folha de freqüência deverá ser entregue junto com as exigências 2, 5, 6 e 7, na sexta-feira da penúltima semana do curso. Ainda assim, continue controlando sua freqüência para você completar sua folha, na ocasião da entrevista individual de avaliação.

\section{Diário de Vivência Pessoal}

Deverá ser iniciado no primeiro dia do curso; nele, você registrará as diferentes atividades que realizar no decorrer da disciplina, sejam elas de campo de estágio, de sala de aula, leituras individuais e/ou de grupo, preparo de trabalhos, experiências pessoais, contatos com outras pessoas..., enfim toda atividade que você desenvolver no curso.

Além de registrar as atividades realizadas, registre também o significado pessoal que cada uma delas teve para você. Lembre-se de que quanto mais aberta e honesta você for consigo mesma, maior progresso alcançará. 
A finalidade desta segunda exigência é facilitar seu autoconhecimento - ter contato próximo e profundo com você mesma e com tudo que esteja acontecendo consigo - acreditamos que esse autoconhecimento a auxiliará na identificação de sues objetivos; na seleção dos meios a utilizar e facilitará sua avaliação.

O diário de vivência pessoal deverá ser entregue junto com as próximas exigências, na sexta-feira da penúltima semana do curso.

\section{Contrato Pessoal de Trabalho}

Este contrato deverá conter informações sobre:

- seus objetivos de aprendizagem neste curso;

- os meios que você utilizará para atingí-los; e

- os critérios que você estabelecerá e empregará na sua avaliação.

Acreditamos que, ao preencher seu contrato, você perceberá mais claramente o que quer aprender nesta disciplina, os recursos que facilitarão sua aprendizagem, bem como aspectos que você julgar importantes para avaliar a extensão e o significado de sua aprendizagem.

A apresentação deste contrato escrito deverá acontecer no quarto dia do curso, após você ter tomado contato com os recursos oferecidos pela disciplina, e como resultado da primeira reunião de pequeno grupo, a qual será destinada a facilitar a identificação de suas necessidades pessoais e a formulação de seus objetivos de aprendizagem.

\section{Contrato Semanal de Trabalho e Avaliação Semanal}

No inicio de cada semana de estágio e, como resultado de uma reunião de grupo de estágio, você deverá preencher e entregar um Contrato Semanal de Trabalho. Nele você deverá registrar seus objetivos de aprendizagem para essa semana, bem como os recursos que utilizará para antingi-los.

A finalidade desses contratos é facilitar seu aproveitamento nas atividades práticas, como também orientar a docente que a acompanhar no campo, quanto aos recursos a serem providenciados para você, bem como aqueles que ela julgar possam contribuir à consecução de seus objetivos.

No último dia de cada semana de estágio, após a reunião de pequeno grupo, você deverá preencher e entregar sua própria avaliação do seu desempenho nessa semana, incluindo nela quais e o quanto de seus objetivos você conseguiu atingir, bem como os fatores que, na sua opinião, facilitaram e/ou dificultaram esse resultado.

Nossa intenção ao lhe exigir as avaliações semanais é facilitar-lhe a formulação de objetivos para as semanas seguintes, bem como a de facilitar-lhe a compreensão e o treino da auto-avaliação como um processo contínuo, essencial à aprendizagem significativa. Acreditamos que as avaliações semanais a ajudarão, também, a perceber o surgimento de 
novas motivações e, portanto, de objetivos de aprendizagem diferentes daqueles que você registrara no seu Contrato Pessoal de Trabalho.

\section{Trabalho Escrito}

Nele você deverá apresentar uma experiência significativa para você, seja ela uma leitura, uma conversa, uma experiência em campo de estágio, um apanhado do seu diário de vivências neste curso, interações pessoais, etc.

Para ser uma experiência significativa ela deverá ter a qualidade de envolvimento pessoal - você inteira, sentimentos e idéias participando dela, e que tenha provocado mudanças em você: mudanças de percepção, de comportamento ou de atitudes.

Queremos discutir esse trabalho com você antes do término do curso. Assim sendo você dispõe até a sexta-feira da penúltima semana do curso para a entrega do mesmo.

\section{Auto-Avaliação Final}

Para atender a esta exigência você deverá nos comunicar por escrito, em impresso próprio oferecido pela disciplina, a avaliação do seu desempenho no curso e de seus progressos, mencionando, também, os critérios que seguiu para julgá-los. Esta avaliação deverá conter DUAS NOTAS, uma para as atividades teóricas e outra para as práticas.

\section{Avaliação da Discipliná}

Esta deverá incluir a sua reação pessoal à disciplina como um todo. Gostariamos que você declarasse com a maior honestidade o que ela significou para você, tanto positiva quanto negativamente.

Estimaremos qualquer crítica que você fizer ao curso, bem como sugestões para aperfeiçoá-lo. É, em resumo, a sua oportunidade de avaliar o curso, as docentes, os recursos que foram oferecidos e a maneira como o curso aconteceu. Isso não influirá em sua nota, mas, se você achar que pode haver qualquer influência, entregue a sua avaliação em um envelope fechado com o seu nome na parte externa junto com uma observação tipo: "Favor não abrir até que as notas finais sejam entregues." Se puser isso no envelope, asseguramo-lhes que o seu pedido será respeitado.

Consideramos a avaliação do curso como uma exigência, porque vemos nela mais um recurso para facilitar sua compreensão do processo ocorrido em você, como também por ser um meio de avaliar os recursos que oferecemos, bem como o nosso desempenho no processo de aprendizagem (é nosso feed-back!)

\section{ENTREVISTA INDIVIDUAL DE AVALIAÇĀO}

Uma de nós, tanto quanto possivel aquela com quem você tiver relacionamento mais significativo, terá a responsabilidade de ler todo seu 
material (exigências). Reservamos a quarta e quinta-feira da última semana do curso para realizar a entrevista de avaliação, oportunidade na qual pretendemos, com você, refletir sobre o conteúdo de seu material e trocar percepções sobre o significado de mais diferentes experiências durante o curso, bem como sobre o significado das exigências que the foram solicitadas.

Se nós acharmos que sua avaliação é muito diferente da nossa percepção e compreensão de seu desempenho no curso, aproveitaremos a ocasião da entrevista para, juntas, vermos se nos é possivel chegar a um conceito que satisfaça a ambas partes, você e nós; e que nós, em sã consciência, passamos assinar e registrar.

É importante ressaltar que não se dará nota final até que as sete (7) exigências do curso sejam satisfeitas.

Observaçōes:

1. Recomendamos que você realize outras leituras deste material. Temos a certeza de que a cada nova leitura, sua percepção do conteúdo mudará e a compreensão de sua vivência neste curso aumentará;

2. É provável que, através da leitura, você tenha percebido que escrevemos tudo no feminino. A razão? É a seguinte: tentamos estabelecer com você um CONTATO DE PESSOA PARA PESSOA e, sendo a maioria dos integrantes do nosso grupo do sexo feminino, achamos que este tratamento no feminino facilitaria.

\section{BIBLIOGRAFIA CONSULTADA}

HUTTER, J.D. Manual de instruções. Original não publicado. 1983.

ROGERS, C.R. Liberdade para aprender. 4. ed., Belo Horinzote, Interlivros, 1977. $330 \mathrm{p}$.

Liberdade de aprender em nossa década. Porto Alegre, Artes Médicas, $1985.334 \mathrm{p}$.

\section{ANEXO 1}

\section{NOSSA PEROEPCAO DO PERFIL DA ENFERMEIRA PEDIATRICA}

A enfermeira pediátrica executa tarefas similares às da enfermeira geral e presta assisténcia à crianca sadia ou doente e a sua familia, desempenhando basicamente as seguintes funções:

- utilizando meios apropriados, verifica o "funcionamento da criança" a fim de identificar áreas que necessitam de intervenção para a promoção de seu crescimento e desenvolvimento. Por funcionamento da criança entendemos: "como a criança é", ou seja, a sua capacidade (motora, de linguagem, adaptativa e social), suas necessidades e a maneira como elas são atendidas;

- reconhece e compreende as manifestações de doença na criança, bem como as reações à. doença e à hospitalização, tanto da criança como de sua família, e utiliza recursos apropriados no atendimento acs mesmos, nesses momentos de crise.

Para o desempenho eficiente destas funções básicas, a enfermeira pediátrica deve ter adquirido destreza na execução de procedimentos de enfermagem pediátrica, além de habilidade em técnicas de comunicação e relacionamento de ajuda. 


\section{ANEXO 2 \\ CONTEUDO BASICO QUE FACHLITA O TORNAR-SE ENFERMEIRA EM PEDLATRIA}

\section{PRINCIPIOS DE COMUNICAÇAO E RELACIONAMENTO COM}

1. criança e familia

2. equipe de saúde

II. A ENFERMEIRA E A CRIANÇA

1. O que caracteriza a criança quanto a

a. Crescimento e Desenvolvimento: principios, teorias e marcos. Importancia desses conhecimentos para a enfermeira.

b. Fatores que contribuem para que uma criança seja sadia: necessidades da criança e seu atendimento.

2. Papel da enfermeira junto à crianca sadia

a. Avaliar o funcionamento da criança:

- Meios para avaliar a criança: entrevista, exame físico e aplicação de testes.

- Importância da avaliação da criança para a assistência de enfermagem.

b. Planejar e executar ações de enfermagem que visem à promoção do crescimento e desenvolvimento da criança.

c. Relacionar-se com a equipe de saúde para o atendimento à criança sadia.

III. A ENFERMEIRA E A CRIANÇA DOENTE

1. Aspectos sociais da doença na criança brasileira.

a. Dados estatísticos de morbidade e mortalidade infantil.

b. Fatores determinantes das doenças evitáveis na criança.

c. Recursos assistenciais para atendimento à criança doente e critérios de procura e utilização desses recursos.

d. Porque e quando a criança é hospitalizada.

e. Atuação da enfermeira para possíveis modificações dessa realidade.

2. O impacto da doença e da hospitalização na criança e sua família.

a. Reações da criança e família à doença e à hospitalização.

b. Recursos essenciais para o atendimento à criança e família durante a hospitalização da criança.

- Ambiente físico e sua organização.

- Comunicação aplicada a situações especificas:

- com a criança $\left\{\begin{array}{l}\text { - processo de adaptação } \\ \text { - preparo para experiências difíceis } \\ \text { - utilização do brinquedo }\end{array}\right.$ 
- com a família $\left\{\begin{array}{l}\text { - admissão e alta } \\ \text { - mães visitantes e mães acompanhantes }\end{array}\right.$

- com a equipe $\left\{\begin{array}{l}\text { - passagem de plantão } \\ \text { - prescrição de enfermagem } \\ \text { - relacionamento entre os elementos da equipe }\end{array}\right.$

- comunicação com a criança, familia c equipe na situação especifica de morte.

\section{Assistência de enfermagem à criança hospitalizada e sua familia.}

a. Objetivos do papel da enfermeira em unidade pediátrica.

b. O papel especifico da enfermeira: aplicar metodologia cientifica na assi6tência de enfermagem à criança e sua família. talizada:

c. Características da intervenção de enfermagem junto à criança hospi-

- no atendimento às necessidades comuns da criança.

- no atendimento às necessidades da criança determinadas pela doença e hospitalização.

d. Assistência de enfermagem à criança com as alterações de saúde mais frcquientes em nosso meio:

- alterações do equilibrio hidro-eletrolitico;

- alterações das eliminações;

- alterações da nutrição; e

- alterações da respiração.

\section{ANEXO 3}

\section{RECURSOS A SUA DISPOSICAO NESTE CURSO}

-- Expcriências em instituições de atendimentos à criança;

- nós, as facilitadoras de seu curso;

- monitora(s) - facilitadora(s);

- profissionais da áreas pediátrica;

- material bibliográfico;

- leituras individuais e em grupo;

- grupos de discussão;

- palestras;

- aulas;

- demonstrações;

- seminários;

- mesas redondas;

- relatos de experiências;

- apresentação e discussão de casu;

- dramatização;

- visitas a instituições de assistência à criança; e

- tantas outras atividades que você possa imaginar e queira desenvolver conosco... 


\section{ANEXO 4 \\ BIBLIOGRAFIA BASICA *}

AlCantara, P. et alii. Mãe e filho. 5. ed. São Paulo, Almed, 1980.

alcantara, P. \& MARCondes, E. Pediatria básica. 7. ed. São Paulo, Sarvier, 1985.

ALEXANDER, M.M. \& BROWN. M.S. Diagnóstico na enfermagem pediátrica. São Paulo, Andrei, 1978.

BERNARD, K. \& ERICKSON, N. Como educar crianças com problemas de desenvolvimento. Porto Alegre, Globo, 1979.

BOWLBY, J. Cuidados maternos e saúde mental. São Paulo, Martins Fontes, 1981.

EPSTEIN, C. Interação efetiva na enfermagem. São Paulo, E.P.U., 1977.

GINOTT, H. Pais e filhos. 6. ed. Rio de Janeiro, Bloch, 1975.

KRON, T. Manual de enfermagem. 4. ed. Rio de Janeiro, Interamericana, 1978.

LIRA, M.J. Primer año de vida - manuales de estimulaciōn. Buenos Aires, Galdoc, 1979.

LIRA, M.J. Segundo año de vida - manuales de estimulación. Buenos Aires, Galdcc, 1979.

MACHADO, D.M. Ação psicoprofilática do pediatra. São Paulo, Sarvier, 1979.

MALDONADO, M.T. Comunicação entre pais e filhos - a linguagem do sentir. 5. ed., Petrópolis, Vozes, 1984.

MARCONDES, E. Desidratação. São Paulo, Sarvier, 1976.

MARCONDES, E. Desnutrição. São Paulo, Sarvier, 1976.

MARCONDES, E. Pediatria - doutrina e ação. São Paulo, Sarvier, 1977.

MARCONDES, E. \& MANISSADJIAN, A. Terapêtica pediátrica. São Paulo, Sarvier, 1977.

MARLOW, D. Enfermaria pediátrica. 4. ed. México, Interamericana, 1979.

MIRANDA, C.F. \& MIRANIDA, M.L. Construindo a relacão de ajuda. Belo Horizonte, Crescer, 1983.

MORLEY, D. et alii. Prioridades en la salud infantil. México, Pax, 1977.

MURAhOVSCHI, J. Emergências em pediatria. 4. ed. São Paulo, Sarvier, 1981.

PETRILLO, M. \& SANGER, S. Cuidado emocional del niño hospitalizado. México, La Prensa Médica Mexicana, 1975.

PLANK, E. El cuidado psicológico del niño enfermo en el hospital. Buenos Aires, Paidós, 1968.

ROGERS, C.R. \& ROSENBERG, R.L. A pessoa como centro. São Paulo, E.P.U., EDUSP, 1977.

ROGERS, C.R. Liberlade para aprender. Belo Horizonte. Interlivros de Minas Gerais, 1978.

\footnotetext{
* Querendo se aprofundar em qualquer assunto de enfermagem pediátrica
} é só solicitar orientação em relação a outros recursos bibliográficos. 
SCIPIEN, G.M. et alii. Comprehensive pediatric nursing. New York, MacGraw-Hill, 1975.

SMITH, M. et alii. Child and family: concepts of nursing practice. New York, MacGraw-Hill, 1982.

WERNER, D. Onde não há médico. 5. ed. São Paulo, Edições Paulinas, 1977.

WAECHTER, E. \& BLAKE, F. Enfermagem pediátrica. 9. ed. Rio de Janeiro, Interamericana, 1978.

WHALEY, L.F. \& WONG, D.L. Essentials of pediatric nursing. 2. ed. St. Louis, Mosby, 1985.

WONG, D.L. \& WHALEY, L.F. Clinical handbook of pediatric nursing. St. Louis, Mosby, 1981.

Além desses, você tem à sua disposição um conjunto de apostilas, elaboradas por nós, abrangendo temas referentes ao conteúdo indicado no anexo 2.

\section{CONSIDERAÇÕES FINAIS}

O material apresentado, que constitui a mecânica da disciplina Enfermagem Pediátrica I, tem se mostrado eficaz para facilitar a compreensão do seu funcionamento.

E importante salientar que esse recurso, por nós escolhido, venha sofrer modificações, à medida em que nos desenvolvemos na facilitação da aprendizagem de enfermagem pediátrica.

No ensino centrado no estudante, cada novo passo experimentado fornece novos conhecimentos, possibilitando ao professor empregar inovações mais efetivas e abrangentes, que proporcionem a liberdade responsável em sala de aula. E sem dúvida, um trabalho gradativo de crescimento tanto do professor como dos alunos.

NEIRA HUERTA, E. del P.; ANGELO, M.; RIBEIRO, M.O.; HORTA, A.L. de M. Student - centered teaching: orientation to the undergraduate Pediatric Nursing

Course. Rev. Esc. Enf. USP, São Paulo, 20(2):101-114, 1986.

The authors present the matcrial currently being used in the orientation phase of the Pediatric Nursing I Course, which utilizes the student - centered teaching methodology, at the Nursing School of the São Paulo University.

\section{REFERENCIAS BIBLIOGRÁFICAS}

1. MORAES, E. O ensino de Enfermagem Pediátrica ao nivel de graduação. Rev. Esc. Enf. USP., São Paulo, 15(2):193-203, 1981.

2. MORAES, E. \& PAULA, M. do A. de. Como percebi a ineficiência do ensino de Enfermagem Pediátrica no aspecto referente à assistência ans pais. Rev. Esc. Ent. USP., São Paulo,, 14 (3) :243-56, 1980.

3. NEIRA HUER'TA, E. del $P$. et alii. O curso de Enfermagem Pediátrica I na Escola de Enfermagem da USP. Rer. Esc. Ent. USP., São Paulo, 19(3):247-262, 1985.

4. NEIRA HUERTA, E. del P. \& ANGELO, M. Ensino centrado no estudante: evolução do inficio do curso Enfermagem Pediátrica - nível graduação. Rev. Esc. Enf. lisP., São Paulo, 20(1):19-25, 1986.

5. RIBEIRO, C.A. et alil. A disciplina Enfermagem Pediátrica: avaliação, pelos alunos, de uma nova metodologia de ensino. Rer. Esc. Enf. USP., Săo Paulo, 16(2):181-92, 1982. 